\title{
Involvement of the carboxyl terminus of vertebrate poly(A) polymerase in U1A autoregulation and in the coupling of splicing and polyadenylation
}

\author{
Samuel I. Gunderson, ${ }^{1}$ Stéphan Vagner, Maria Polycarpou-Schwarz, and Iain W. Mattaj ${ }^{2}$ \\ European Molecular Biology Laboratory, D-69117 Heidelberg, Germany
}

\begin{abstract}
Interactions required for inhibition of poly(A) polymerase (PAP) by the U1 snRNP-specific U1A protein, a reaction whose function is to autoregulate U1A protein production, are examined. PAP inhibition requires a substrate RNA to which at least two molecules of U1A protein can bind tightly, but we demonstrate that the secondary structure of the RNA is not highly constrained. A mutational analysis reveals that the carboxy-terminal 20 amino acids of PAP are essential for its inhibition by the U1A-RNA complex. Remarkably, transfer of these amino acids to yeast PAP, which is otherwise not affected by U1A protein, is sufficient to confer U1A-mediated inhibition onto the yeast enzyme. A glutathione $S$-transferase fusion protein containing only these 20 PAP residues can interact in vitro with an RNA-U1A protein complex containing two U1A molecules, but not with one containing a single U1A protein, explaining the requirement for two U1A-binding sites on the autoregulatory RNA element. A mutational analysis of the U1A protein demonstrates that amino acids 103-119 are required for PAP inhibition. A monomeric synthetic peptide consisting of the conserved U1A amino acids from this region has no detectable effect on PAP activity. However, the same U1A peptide, when conjugated to BSA, inhibits vertebrate PAP. In addition to this activity, the U1A peptide-BSA conjugate specifically uncouples splicing and 3 '-end formation in vitro without affecting uncoupled splicing or 3 '-end cleavage efficiencies. This suggests that the carboxy-terminal region of PAP with which it interacts is involved not only in U1A autoregulation but also in the coupling of splicing and 3 '-end formation.
\end{abstract}

[Key Words: RNA processing; pre-mRNA splicing; cleavage and polyadenylation; U1A protein; poly(A) polymerase]

Received October 9, 1996; revised version accepted February 4, 1997.

The $3^{\prime}$ ends of most eukaryotic mRNAs consist of a homopolymer of adenosine residues, called the poly(A) tail, ranging from 20 to 200 nucleotides in length. The poly(A) tail is added to pre-mRNA post-transcriptionally in the nucleus by a two step process called cleavage and polyadenylation (for review, see Manley and Proudfoot 1994; Keller 1995; Manley 1995; Wahle 1995). Cleavage and polyadenylation of pre-mRNAs is best characterized in vertebrates. The common RNA signals required for efficient cleavage and polyadenylation are the essential A(A/U)UAAA hexanucleotide (Proudfoot and Brownlee 1976) and a G/U-rich sequence (MacDonald et al. 1994) that lie respectively upstream and downstream of the cleavage site. For the cleavage step a heterotetrameric complex called CPSF (cleavage and polyadenylation

\footnotetext{
${ }^{1}$ Present address: Department of Molecular Biology and Biochemistry, Rutgers University, Nelson Labs-Busch Campus, Piscataway, New Jersey 08855 USA.

${ }^{2}$ Corresponding author.

E-MAIL mattaj@embl-heidelberg.de; FAX +6221 387518.
}

specificity factor) binds to the highly conserved A(A/ U)UAAA sequence (Bienroth et al. 1991; Murthy and Manley 1992) and a heterotrimeric complex, CStF (cleavage stimulatory factor), to the G/U-rich element (Takagaki et. al. 1990; Gilmartin and Nevins 1991). Once bound to the RNA substrate, CPSF and CStF are presumed to interact with cleavage factors (CF) I and II. Recently CFI has been characterized biochemically (Rüegsegger et al. 1996) and is believed to consist of three polypeptides. CFII is still poorly characterized. In addition to these four essential factors, poly(A) polymerase (PAP) is also required for the efficient cleavage of at least some vertebrate pre-mRNAs in vitro (Christofori and Keller 1988; Takagaki et al. 1989).

After assembly of these factors the pre-mRNA is cleaved endonucleolytically at a site $\sim 15-30$ nucleotides downstream of the A/A/U/UAAA sequence. The downstream or $3^{\prime}$ cleavage product is degraded rapidly while the upstream or $5^{\prime}$ cleavage product undergoes the second processing step, polyadenylation. In vitro, this reaction requires only CPSF and PAP, but is only efficiently 
processive, and subject only to poly(A) length control, in the presence of poly(A) binding protein II (Wahle 1991b).

One of the best-characterized examples of the regulation of mRNA 3 '-end formation at the molecular level is the autoregulation of the polyadenylation of UlA premRNA by the human U1 small nuclear ribonucleoprotein (snRNP)-specific U1A protein (for review, see Proudfoot 1994; Lewis et al. 1995). Aside from its role in regulation of polyadenylation (discussed below), the U1A protein is part of the U1 snRNP, which functions in splice site recognition during pre-mRNA splicing. Although there is evidence that both vertebrate (Hamm et al. 1990) and yeast (Liao et al. 1993; Tang and Rosbash 1996) U1A proteins have a role in pre-mRNA splicing, its detailed function in the Ul snRNP is unknown. UlA belongs to a large family of proteins that contain one to several copies of a conserved domain of $\sim 80-90$ residues called the RNA recognition motif (RRM) or ribonucleoprotein (RNP) motif (for review, see Mattaj 1993; Burd and Dreyfuss 1994). The UlA protein contains 2 RRMs, located at the amino and carboxyl termini of the protein, separated by a unique middle region (Sillekens et al. 1987).

UlA protein binds with high affinity and specificity to the loop sequence AUUGCAC found in the second stem-loop of U1 snRNA (Lutz-Freyermuth et al. 1990; Scherly et al. 1989, 1990; Stump and Hall 1995). Biochemical and mutational analysis has demonstrated that the amino-terminal RRM plus a few additional flanking residues (residues 1-101) are sufficient for specific RNA binding. The structure of the amino-terminal domain has been solved both alone and in complex with stemloop 2 of U1 snRNA (Nagai et al. 1990; Hoffmann et al. 1991; Oubridge et al. 1994). This amino-terminal region of UlA protein also binds specifically to two loop sequences, AUUGCAC and AUUGUAC, found in the $3^{\prime}$ untranslated region (UTR) of the UlA pre-mRNA /van Gelder et al. 1993). This interaction is responsible for U1A protein autoregulation. The structure of an aminoterminal fragment of U1A protein bound to one of the two U1A protein-binding sites on the U1A pre-mRNA has been solved (Allain et al. 1996) and models of the binding of two UlA molecules to the two pre-mRNA binding sites have been proposed (Allain et al. 1996; Avis et al. 1996; Jovine et al. 1996).

The mechanism whereby the UlA protein regulates the polyadenylation of its own pre-mRNA has been determined. When full-length UlA protein binds to the U1A pre-mRNA regulatory element, it prevents cleavage and polyadenylation of U1A pre-mRNA (Boelens et al. 1993; van Gelder et al. 1993). The inhibitory U1A premRNA-U1A protein complex binds directly to PAP (Gunderson et al. 1994). Here we analyze the molecular interactions required for this regulatory event, and define short peptide sequences in both the PAP and UlA proteins required for their interaction and for PAP inhibition.

Many pre-mRNAs are not only polyadenylated, but also spliced, and there is evidence that splicing and 3 'end formation are linked. Antisera that recognize U1 sn-
RNP components were shown to inhibit cleavage and polyadenylation (Moore and Sharp 1985; Hashimoto and Steitz 1986). In addition, coimmunoprecipitation experiments showed that a small fraction of U1 snRNP is found in complex with PAP (Raju and Jacob 1988). Although U1 snRNP is not required for cleavage and polyadenylation, a rationale for these observations came with the discovery that splicing and cleavage/polyadenylation can be mutually stimulatory, coupled events both in vivo and in vitro (Niwa et al. 1990; Niwa and Berget 1991). The presence of functional signals for cleavage and polyadenylation can stimulate removal of the $3^{\prime}$-most intron in a pre-mRNA. U1 snRNP was implicated in this phenomenon by the observation that weak sites of interaction with U1 snRNA lying between the $3^{\prime}$-most intron and the AAUAAA signal of an SV40 late pre-mRNA were required for coupling to occur in vitro (Wassarmann and Steitz 1993). Other studies have shown that the U1A protein can stimulate the polyadenylation reaction (Lutz et al. 1996). These results imply the existence of an as yet undefined interaction between the splicing and 3 '-end formation machineries. Having defined the regions of U1A protein and PAP required for autoregulation, we go on to show that a U1A peptide conjugate that interacts with the carboxyl terminus of PAP uncouples splicing and 3 '-end formation, suggesting that the PAP carboxyl terminus may be required for the stimulation of splicing by the 3 '-end formation machinery.

\section{Results}

The secondary structure of polyadenylation inhibitory element RNA is not strictly required for U1A inhibition of polyadenylation

A 100 nucleotide RNA sequence derived from the $3^{\prime}$ UTR of the U1A pre-mRNA, PIE (polyadenylation inhibitory element) RNA, is sufficient to support U1A autoregulation both in vitro and in vivo (Boelens et al. 1993). PIE RNA (van Gelder et al. 1993) contains two UlA protein-binding sites and the U1A pre-mRNA cleavage and polyadenylation signal (Fig. 1). Much of the secondary structure is required for binding two molecules of U1A protein and for U1A autoregulation (van Gelder et al. 1993). The evolutionary conservation of PIE RNA and its ability to support cooperative binding of two molecules of UlA protein suggested that it might serve as more than just a binding scaffold. To determine the requirement for this secondary structure, we replaced it with two copies of a high-affinity binding site for U1A protein derived from stem-loop 2 of U1 snRNA. In this RNA (designated SL2/SL2) the sequence shown in Figure 2A is inserted into PIE RNA in place of the complex U1A-binding stem-loop structure. The minimum high-affinity U1A protein binding site consists of a 3-bp stem and a 7 -nucleotide loop sequence, AUUGCAC (Lu and Hall 1995). To ensure the two artificial U1A binding sites would have a high probability of adopting this desired secondary structure, the loops were held in place by 


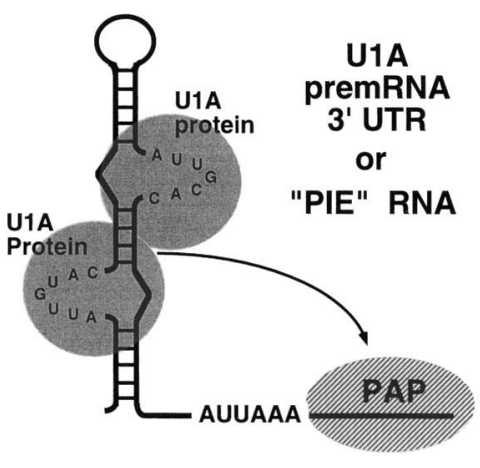

Figure 1. Model of inhibition of PAP by the U1A protein-PIE RNA complex. Two molecules of U1A protein (shaded circles) are shown bound to the PIE RNA of the U1A pre-mRNA in the region near the polyadenylation signal (AUUAAA). The two loop sequences (AUUG(C/U)AC) and much of the secondary structure are required for binding two molecules of U1A protein. The arrow indicates that the UlA protein-PIE RNA complex interacts with and inhibits the activity of PAP.

stems rich in $\mathrm{G}-\mathrm{C}$ base pairs. To allow some conformational flexibility the two artificial stem-loops were separated by a 10 -nucleotide linker. This RNA specifically binds two molecules of U1A protein with an affinity approximately equal to that of U1 snRNA (data not shown). In spite of its distant resemblance to PIE RNA, the polyadenylation activity of this RNA in HeLa nuclear extracts was specifically regulated by addition of recombinant U1A protein to a degree similar to that of U1A pre-mRNA (Fig. 2B, lanes 2-5; data not shown; Boelens et al. 1993). When either of the two U1A binding sites was mutated singly, or when both sites were mutated, the regulation of cleavage/polyadenylation by U1A protein was reduced greatly (lanes 6-20). Similar results were obtained when precleaved SL2/SL2 RNA was polyadenylated in the presence of varying amounts of U1A protein either in complete nuclear extract or by recombinant $P A P$ under nonspecific polyadenylation conditions (data not shown). These results confirm that two U1A protein molecules bound to an RNA are needed to inhibit polyadenylation of that RNA. In addition, it seems that PIE RNA contributes to PAP inhibition simply by binding U1A protein.

Two U1A protein-RNA-binding sites in PIE RNA are required for $U 1 A$ protein to interact with bovine PAP

The above experiment and data of van Gelder et al. (1993) establishes that two RNA-bound molecules of U1A are required for polyadenylation inhibition. To determine whether this is also a requirement for direct U1A-PAP interaction, we employed an assay described previously (Gunderson et al. 1994) in which purified recombinant bovine PAP was coupled to Affigel-15, and ${ }^{125}$ I-labeled recombinant U1A protein, either alone or complexed to PIE RNA, was passed over the PAP column. As an internal control a ${ }^{125}$ I-labeled truncated version of U1A protein, $\mathrm{U}_{1 \mathrm{~A}_{101}}$, was used. $\mathrm{U}_{1 \mathrm{~A}_{101}}$ binds to

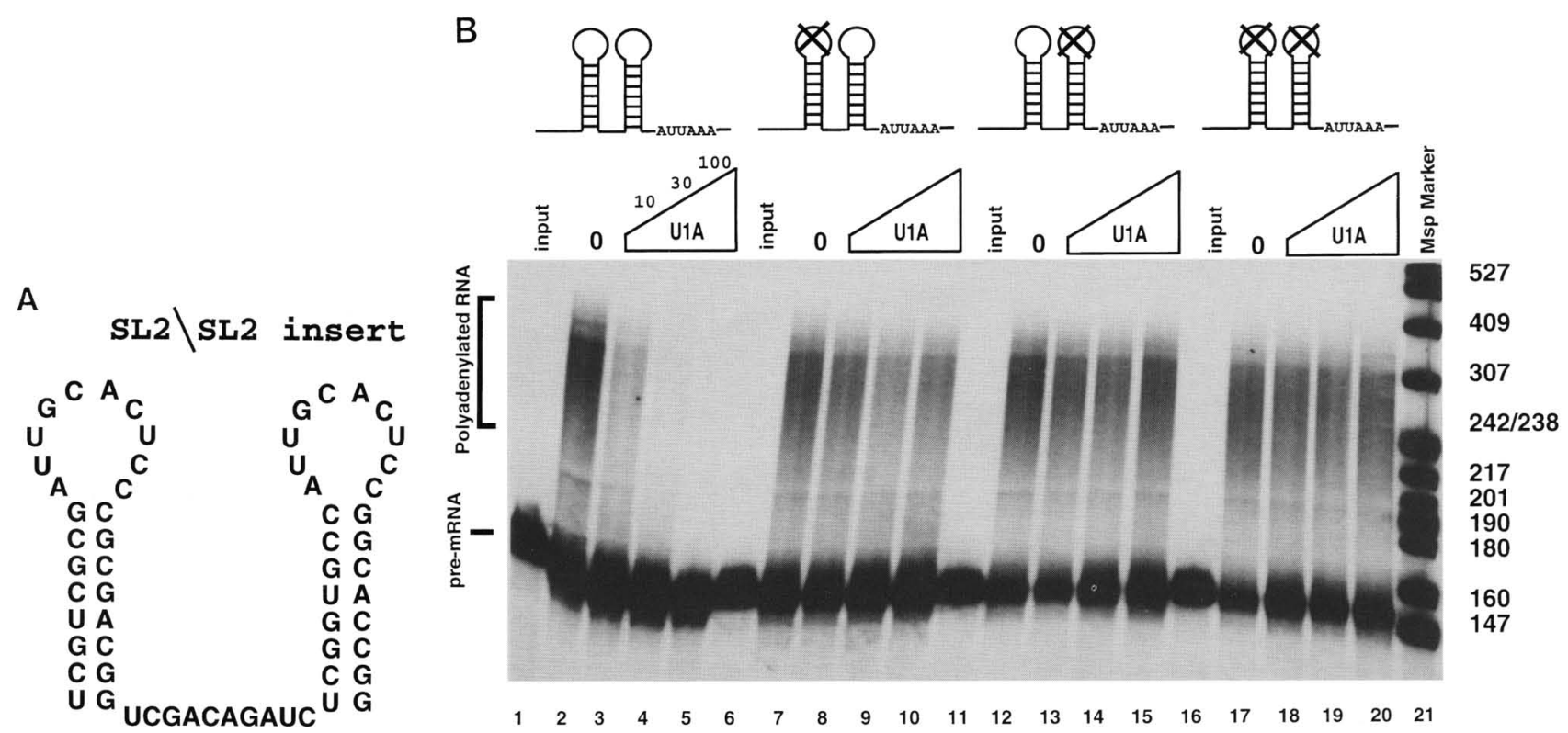

Figure 2. Two high-affinity U1A-binding sites can replace PIE RNA. (A) The sequence and predicted secondary structure of the two tandem hairpin loops inserted in place of the two U1A binding sites of PIE RNA (Fig. 1). Both loop sequences are identical to loop 2 of U1 snRNA but neither stem is identical to stem 2 of U1 snRNA. (B) Regulation of SL2/SL2 RNA cleavage and polyadenylation by U1A protein in HeLa cell nuclear extracts. The ${ }^{32} \mathrm{P}$-labeled SL2/SL2 RNA and mutants were first incubated with recombinant U1A protein for $5 \mathrm{~min}$ and then polyadenylation initiated. Indicated above each panel is the labeled RNA substrate. (Lanes 1,6,11,16) Input RNA; (lanes 2-5,7-10,11-15,16-20) nuclear extract is present. (Lanes 3-5,7-10,13-15,18-20) Recombinant U1A protein is added in nanograms as indicated above the lanes. 
PIE RNA as well as full-length U1A protein but can neither inhibit nor interact with bovine PAP. After extensive washing in low-salt buffer, the bovine PAP column specifically retained the U1A protein-PIE RNA complex, which was eluted in high-salt buffer ( $800 \mathrm{~mm} \mathrm{KCl)} \mathrm{(Fig.} \mathrm{3,}$ lanes 4-6). The U1A $\mathrm{A}_{101}-\mathrm{PIE}$ RNA complex was not retained. To confirm that most of the UlA protein had been eluted, the high-salt step was followed by elution with buffer containing SDS. In the absence of RNA, fulllength U1A protein bound to the PAP column as poorly as $\mathrm{UlA}_{101}$, indicating no specific interaction (Fig. 3, lanes 1-3). In the presence of RNA containing only one of the two U1A protein-binding sites on PIE RNA (lanes 10-15), either no increase or a slight increase (four-fold in the case of the $\Delta$ loop2 mutant RNA) in binding to the PAP column was observed. However, when PIE RNA containing both UlA protein-binding sites (wild-type PIE RNA) was used the affinity of the U1A wild-type protein for the PAP column was stimulated 50-fold above background (lanes $4-6$ ), and $85 \%$ of the labeled U1A protein was retained by the PAP column. In the absence of RNA, there is therefore no detectable binding of U1A protein to PAP and in the presence of a single U1A-binding site, the affinity of the RNA-protein complex for PAP is also low. Parallel experiments were per-

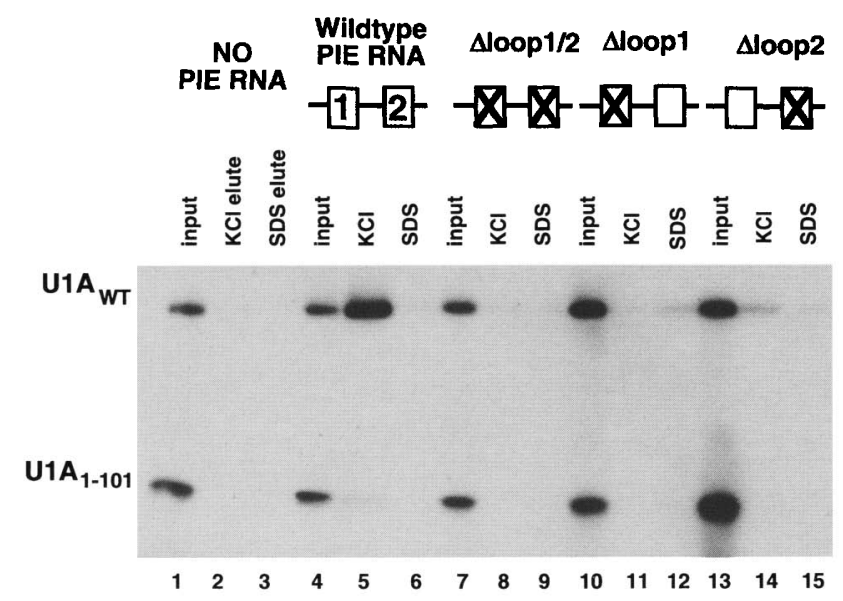

Figure 3. Interaction of the U1A protein-PIE RNA complex with bovine PAP. Interaction between immobilized bovine PAP and the U1A protein-PIE RNA complex was assayed (Gunderson et al. 1994). ${ }^{125}$ I-Labeled U1A protein and ${ }^{125}$ I-labeled $\mathrm{UlA}_{101}$ (negative control) were bound separately as either homodimers or monomers to various unlabeled RNA substrates and then mixed and added to the bovine PAP-Affigel-15 resin. The resin was washed in low salt $(100 \mathrm{~mm} \mathrm{KCl})$ buffer and bound protein-RNA complexes eluted in high-salt buffer 1800 $\mathrm{mM} \mathrm{KCl)} \mathrm{followed} \mathrm{by} \mathrm{SDS} \mathrm{buffer.} \mathrm{The} \mathrm{high-salt} \mathrm{and} \mathrm{SDS} \mathrm{elu-}$ tions were analyzed by SDS-PAGE and autoradiography. (Lanes $1,4,7,10,13) 3 \%$ of the input U1A protein. (Lanes $2,5,8,11,14$ ) $15 \%$ of the high salt elution; (lanes $3,6,9,12,15$ ) $15 \%$ of the SDS elution. RNAs used are indicated above the lanes. (Lanes 1-3) Added RNA is absent (except for tRNA); (lanes 4-6) wild-type PIE RNA; (lanes 7-15) mutant versions of PIE RNA where either loop 1 (lanes 10-12), loop 2 (lanes 13-15), or both loops (lanes 7-9) are mutated. formed using a carboxy-terminal deleted form of bovine PAP (residues 1-520) coupled to Affigel-15. This truncated PAP cannot be inhibited by the U1A protein-PIE RNA complex (Gunderson et al. 1994). No significant binding of either wild-type U1A protein or U1A $\mathrm{A}_{101}$ to this control column was observed (data not shown).

\section{Forty-three carboxy-terminal amino acids of bovine PAP confer $U 1 A$ autoregulation}

We have shown previously that PAP is the sole target of inhibition in the UlA autoregulatory system using a nonspecific polyadenylation assay. A truncation of bovine PAP lacking the carboxy-terminal 219 amino acids neither was inhibited by nor could interact with PIE RNA-bound U1A protein (Gunderson et al. 1994). To more precisely map the region of bovine PAP responsible for autoregulation, PAP truncations (amino acids 1-694 or 1-643) or an internal deletion (amino acids 541-697) were expressed in Escherichia coli, purified, and tested in a nonspecific polyadenylation inhibition assay. Care was taken to ensure the recombinant proteins were of full length (see Materials and Methods). The amino-terminal 530 amino acids were not mutated because several groups have reported that even small deletions in this part of the protein reduce polymerase activity (Raabe et al. 1994; Thuresson et al. 1994; Martin and Keller 1996) and we had shown that bovine PAP1-520 was not inhibited by UlA. The intrinsic polyadenylation activity of the three PAP mutants were similar to that of the fulllength PAP (Fig. 4A, lanes 2,6,10, and 14). Recombinant U1A protein efficiently inhibited polyadenylation by full-length bovine PAP (lanes 2-5); in contrast, polyadenylation of PIE RNA by the 1-694 and 1-643 mutants was not inhibited by UlA protein (lanes 6-13). The PAP mutant lacking amino acids 541-697 was inhibited by U1A protein, like full-length PAP (lanes 14-17). Thus, at least some of the carboxy-terminal 43 residues of bovine PAP are necessary for U1A inhibition.

To determine whether these 43 amino acids would be sufficient for inhibition, they were fused to the carboxyl terminus of yeast PAP, which is not inhibited specifically by the U1A protein-PIE RNA complex (Gunderson et al. 1994; Fig. 4B, lanes 1-4). The slight U1A concentration-independent inhibition of yeast PAP seen is not specific as it is independent of the presence of U1A-binding sites on the RNA (data not shown). The hybrid polymerase was inhibited by U1A protein (Fig. 4B, lanes 5-8). The inhibition was efficient because the inhibition of the hybrid PAP or of full-length bovine PAP was nearly identical (Fig. 4, cf. A and B). These 43 amino acids therefore are not only critical for U1A inhibition but contain all the determinants necessary for inhibition in the context of a PAP.

\section{The extreme carboxy-terminal 20 amino acids of bovine PAP are highly conserved and sufficient to confer $U 1 A$ autoregulation}

PIE RNA is conserved between mammals and amphibia (Boelens et al. 1993; van Gelder et al. 1993). The amino- 
A

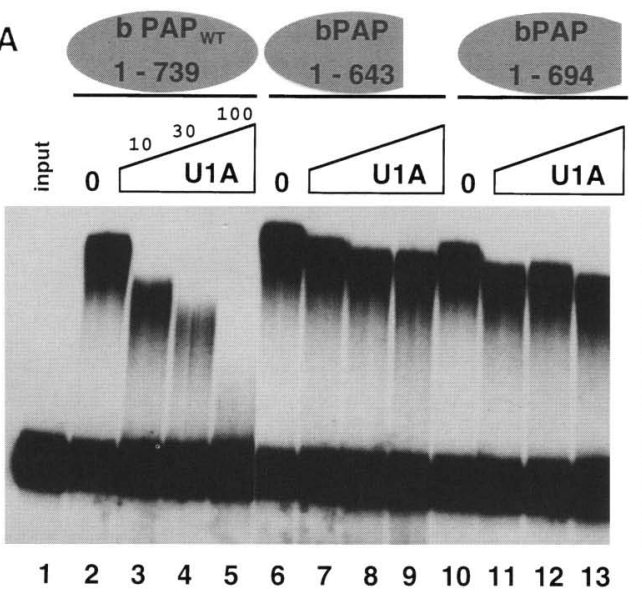

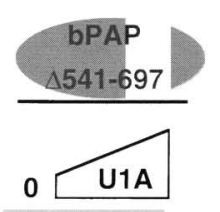

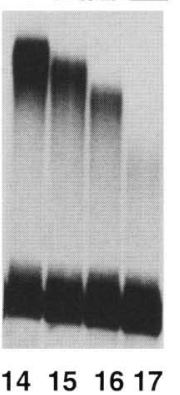

C

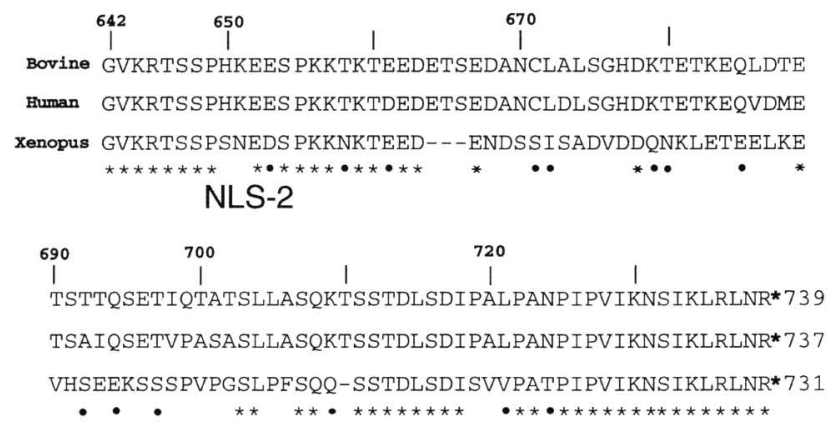

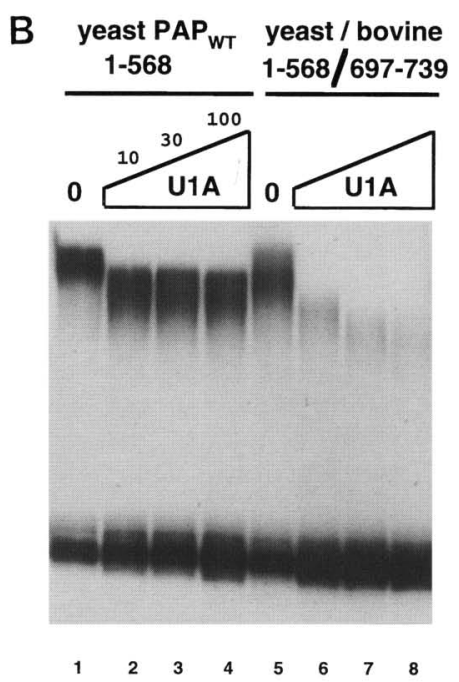
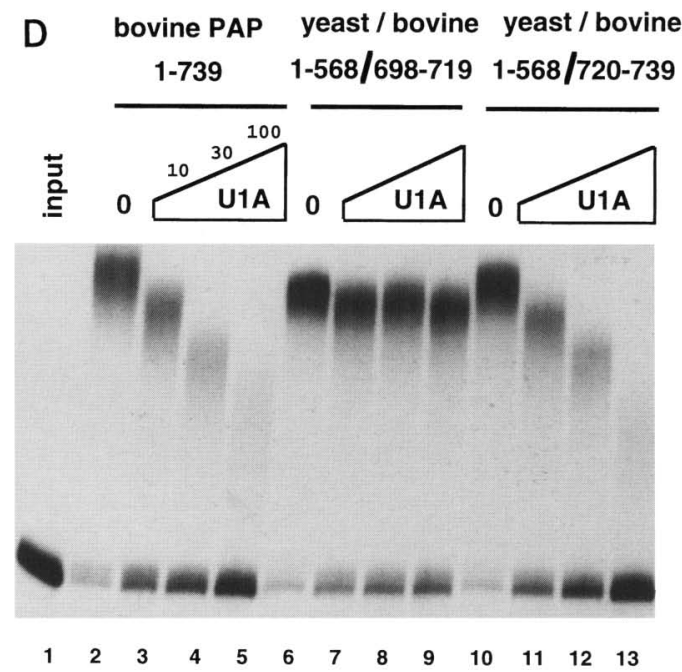

Figure 4. Sensitivity of mutant bovine PAPs and yeast/bovine PAP fusions to U1A inhibition. (A) U1A inhibition requires the carboxy-terminal 43 amino acids of bovine PAP. Carboxy-terminal deletion mutants of bovine PAP were tested in a nonspecific polyadenylation assay for inhibition by the U1A protein-PIE RNA complex. Each lane contains 0.1 pmole (4 ng) of ${ }^{32} \mathrm{P}-\mathrm{labeled}$ substrate PIE RNA. (Lane 1) Input RNA incubated in reaction buffer in the absence of PAP. Lanes 2-5 contain 50 ng bovine PAP; lanes 6-9 contain $40 \mathrm{ng}$ of the 1-643 mutant, lanes 10-13 contain $40 \mathrm{ng}$ of the 1-694 mutant, lanes 14-17 contain $40 \mathrm{ng}$ of the internal deletion mutant (residues 1-540, 698-739). (Lanes 2,6,10,14) U1A protein is absent. (Lanes 3-5,7-9,11-13,15-17) Recombinant U1A protein is as indicated in nanograms. $(B)$ The carboxy-terminal 43 amino acids of bovine PAP transfers UlA protein autoregulation to yeast PAP. The substrate and reaction conditions are as in $A$. Lanes $1-4$ contain $15 \mathrm{ng}$ of full-length yeast PAP; lanes 5-8 contain 15 ng of a yeast-bovine PAP hybrid (bovine PAP residues 698-739 fused to the carboxyl-terminus of full-length yeast PAP). (Lanes 2-4,6-8) Recombinant U1A protein is added as indicated in nanograms. $(C)$ Sequence alignment of the carboxy-terminal 100 amino acids of PAP from cow, human, and Xenopus laevis. Asterisks or dots under the sequences indicate identical or similar amino acids, respectively. The numbers on the right indicate the protein lengths and the asterisk the termination codon. The numbers above the sequences are the amino-acid positions in bovine PAP. $(D)$ The carboxy-terminal 20 amino acids of bovine PAP are sufficient to transfer U1A protein autoregulation. The substrate and reaction conditions are as in $A$. (Lane 1) Input RNA in the absence of added polymerase. Lanes 2-5 contain $50 \mathrm{ng}$ bovine PAP; lanes 6-9 contain $15 \mathrm{ng}$ of a hybrid consisting of bovine PAP residues 698-719 fused to the carboxylterminus of yeast PAP; lanes 10-13 contain $15 \mathrm{ng}$ of a hybrid consisting of bovine PAP residues 720-739 fused to the carboxy-terminus of yeast PAP. (Lanes 3-5,7-9,11-13) Recombinant U1A protein is added as indicated in nanograms.

terminal 500 residues of bovine, human, and Xenopus PAPs are 92\% identical (Raabe et al. 1991; Wahle et al. 1991; Thuresson et al. 1994; Ballantyne et al. 1995; Martin and Keller 1996), but this high degree of conservation diminishes from residues 500 to 600 (73\% identity) and from 600 to the carboxyl terminus $(-140$ amino acids; $48 \%$ identity). Figure $4 \mathrm{C}$ shows the carboxy-terminal region of the known higher eukaryotic PAPs. There are two conserved clusters, one a functional nuclear localization signal (NLS) (Raabe et al. 1994) and the other 
within the 43 amino acids required for U1A inhibition. Strikingly, the last 15 residues are identical both in sequence and in position in vertebrate PAPs (Fig. 4C).

Based on the above data two more yeast/bovine PAP fusions were tested for inhibition by U1A protein. The hybrid PAP containing amino acids $720-739$ from bovine PAP (Fig. 4D, lanes 10-13) was inhibited by UlA protein, indicating that the carboxy-terminal 20 residues of PAP are sufficient for UlA autoregulation. In contrast, transfer of residues 698-719 from bovine PAP to the yeast enzyme did not confer inhibition (lanes 6-9). To confirm the importance of the carboxy-terminal region within the context of full-length bovine PAP, the last eight residues (732-739) were replaced by unrelated amino acids. This bovine PAP mutant was not inhibited /data not shown). Because the conservation of the carboxy-terminal PAP sequences extends beyond residue 720 (Fig. 4C), it appears that amino acids 707-720 are under selective pressure and thus are likely to have some function. However, in our assay, residues 720-739 are sufficient to confer full inhibition onto a heterologous polymerase.

The carboxy-terminal 20 residues of bovine PAP are sufficient for interaction with the U1A protein-PIE RNA complex

Thus, two molecules of U1A bound to an RNA are required for PAP inhibition, and the carboxy-terminal 20 amino acids of bovine PAP are, in the context of yeast PAP, sufficient for PAP inhibition. Because these 20 amino acids exhibit no obvious sequence repetition or duplication, it was of interest to determine whether this carboxy-terminal fragment of PAP would bind to two RNA-bound molecules of U1A but not to a single RNAbound U1A. Electrophoretic mobility shift conditions were established to separate a PIE RNA-(U1A) 2 complex from a single U1A-PIE RNA complex.

Next, a glutathione $S$-transferase (GST) fusion protein containing bovine PAP residues $720-739$ was constructed. A six-histidine tag was placed at the carboxyl terminus of the protein and this tag was used for protein purification. The resulting protein, GST-720/739-HIS, was expressed in E. coli and purified to homogeneity. Two control proteins, one containing bovine PAP sequences 698-719, and GST-HIS, with no insert, were also purified. These three proteins were added to PIE RNA-UlA protein mixtures titrated such that $>90 \%$ (Fig. 5, lanes 2-8) or $\sim 50 \%$ (lanes $10-16$ ) of the proteinbound RNA was associated with two U1A molecules and the remainder with one U1A molecule. The addition of GST-HIS or GST-698/719-HIS had no effect on the RNP complexes containing a single U1A molecule (Fig. 5, lanes 3-6, 11-14). In contrast, GST-720/739-HIS caused a specific retardation of the complexes containing two U1A molecules (Fig. 5, lanes 7,8,15,16).

\section{Residues 103-119 of U1A protein are necessary to inhibit PAP}

The amino-terminal 101 amino acids of U1A protein are

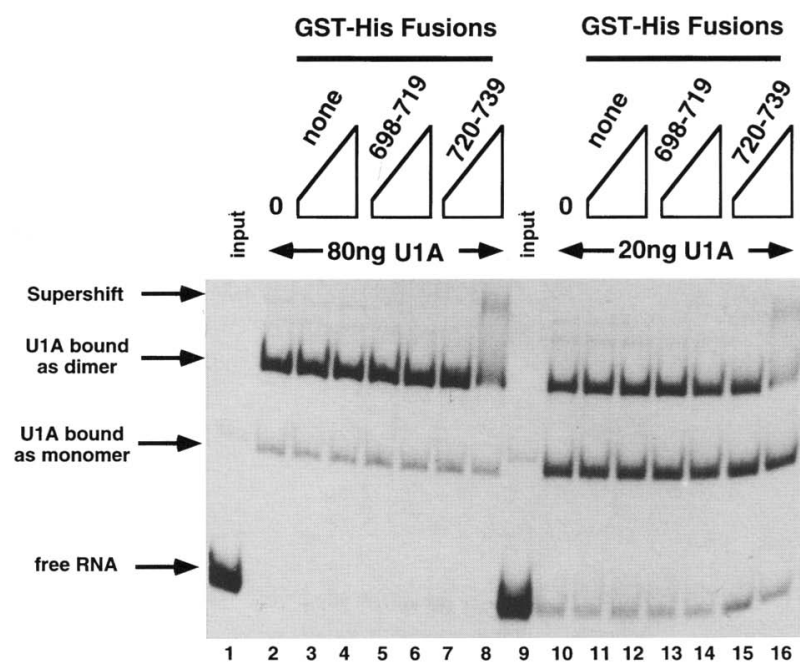

Figure 5. Carboxy-terminal residues of bovine PAP interact with the U1A protein-PIE RNA complex. Gel mobility shift analysis of interaction between U1A protein-PIE RNA complex and GST-(HIS) fusion proteins. (Lanes 1,9) Input PIE RNA. Lanes $2-8$ contain $80 \mathrm{ng}$ of U1A protein, and $-90 \%$ of the RNA is bound to two molecules of U1A protein. Lanes 10-16 contain $20 \mathrm{ng}$ of U1A protein; and $-50 \%$ of the RNA is bound to one and $50 \%$ to two U1A protein molecules. (Lanes 2-8,10-16) An 8× reaction mix was assembled containing labeled RNA, reaction buffer, and U1A protein. This mixture was aliquoted and various GST fusion proteins were added as indicated. Lanes 3 and 11 contain $0.5 \mu \mathrm{g}$ and lanes 4 and 12 contain $3 \mu \mathrm{g}$ of recombinant GST-(HIS) protein. Lanes 5 and 13 contain $0.5 \mu \mathrm{g}$ and lanes 6 and 14 contain $3 \mu \mathrm{g}$ of recombinant GST-(HIS) protein fused to bovine PAP residues 698-719. Lanes 7 and 15 contain $0.5 \mu \mathrm{g}$ and lanes 8 and 16 contain $3 \mu \mathrm{g}$ of recombinant GST-(HIS) protein fused to bovine PAP residues 720-739. The arrows on the left indicate the positions of either the free RNA or RNA-protein complexes.

sufficient for high-affinity PIE RNA binding (van Gelder et al. 1993) but not for PAP inhibition (Gunderson et al. 1994). Furthermore, an analysis of 30 different mutants of this amino-terminal domain in the context of the fulllength protein led to an excellent correlation between the ability of the mutant protein to bind PIE RNA and to interact with PAP (data not shown). This suggested that the UlA protein inhibitory domain would lie outside of the amino-terminal RNA-binding domain. To define this region, various deletion mutants were tested for PAP interaction. For this analysis the U1A protein mutants were labeled with $\left[{ }^{35} \mathrm{~S}\right]$ methionine in vitro. The translation reactions were programmed with U1A mRNA, which contains two U1A protein-binding sites, and it proved unnecessary to add additional unlabeled PIE RNA to observe PAP binding. The translated protein was simply diluted into a suitable buffer and loaded onto the PAP-Affigel resin. The resin was washed in low-salt buffer to remove nonspecifically bound proteins and tightly bound proteins were subsequently eluted in 800 $\mathrm{mM} \mathrm{KCl}$ buffer. Finally, any remaining protein was eluted with SDS-containing buffer. Wildtype and U1A 101 
proteins were included in the binding assay as positive and negative controls. Deletion of either the carboxyterminal RNP motif or most of the central domain had no effect on PAP interaction (U1A $\Delta 203-276$ and $\Delta 138$ 276, Fig. 6A, lanes 5-12). Another internal deletion
(A119-204) removing most of the central domain also had no effect on PAP interaction (Fig. 6A, lanes 13-16). In contrast, removal of residues 103-119 reduced PAP interaction severely (Fig. 6B, lanes 5-8) without affecting binding to PIE RNA (data not shown). To test whether
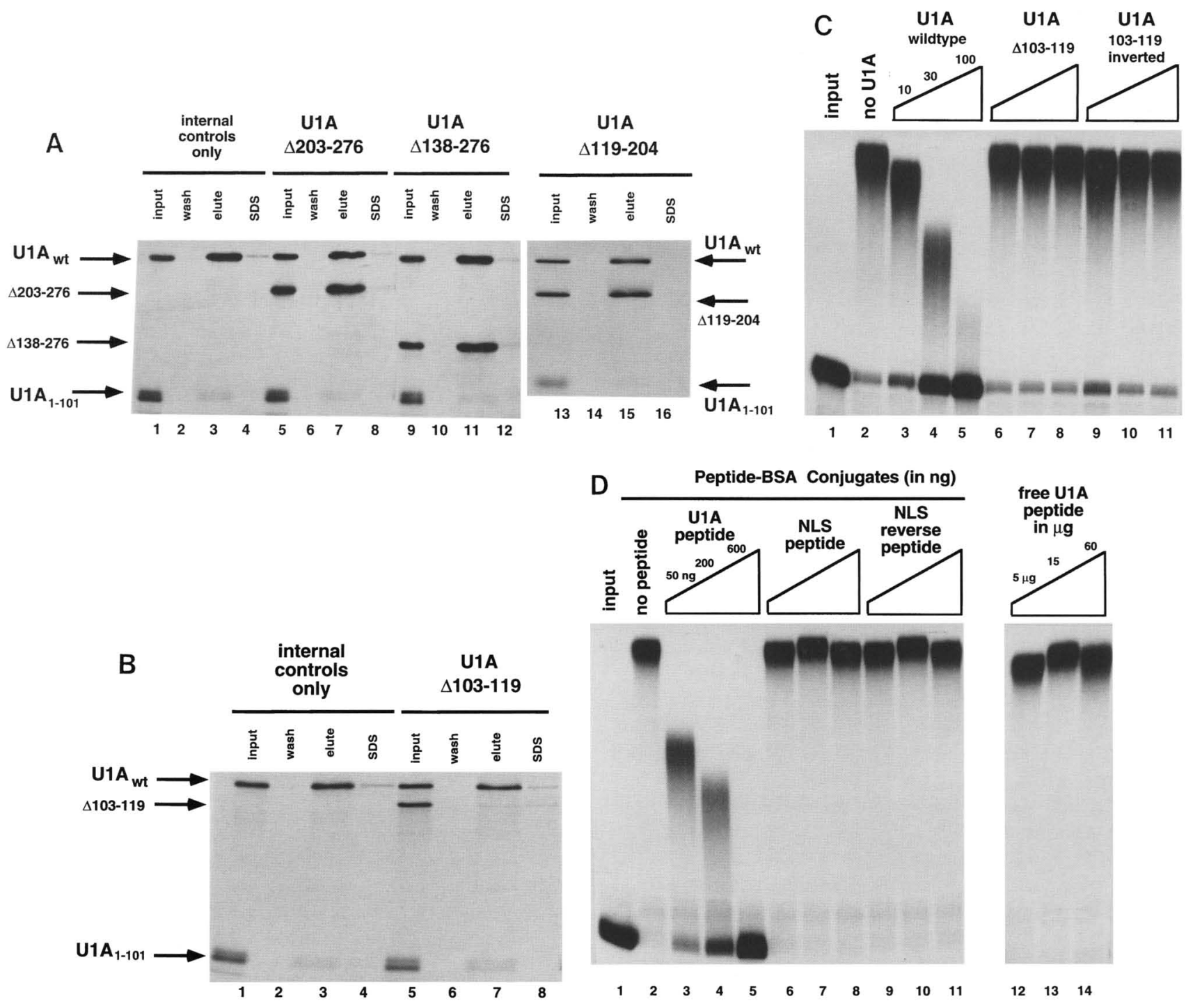

Figure 6. Amino acids 103-119 of U1A protein are required to inhibit bovine PAP. (A) Analysis of human U1A protein mutants. The interaction assay (Fig. 3) with immobilized PAP was used with mutants of human U1A protein. U1A protein and mutants were labeled with $\left[{ }^{35} \mathrm{~S}\right]$ methionine. Wild-type $\mathrm{U} 1 \mathrm{~A}$ and $\mathrm{U} 1 \mathrm{~A}_{101}$ were used as positive and negative internal controls. (Lanes 1-4) Two control proteins alone. In addition, lanes 5-12 contain a U1A mutant lacking residues 203-276; lanes 9-12 contain a mutant lacking residues 138-276; lanes 13-16 contain a mutant lacking residues 119-204. (B) Analysis of a mutant U1A protein lacking residues $103-119$. (Lanes 1-4) U1Awt and U1A $\mathrm{A}_{101}$ alone. Lanes 5-8 contain in addition a mutant U1A protein lacking residues 103-119. (C) Bovine PAP is not inhibited by a mutant U1A protein lacking residues 103-119. Recombinant wild-type or mutant U1A proteins were purified from E. coli. They were then tested in a nonspecific polyadenylation reaction for bovine PAP inhibition as in Fig. 4. (Lane 1) Input RNA. Lanes 2-11 contain 50 ng of recombinant bovine PAP. Additionally, lanes 3-5 contain 20, 60, and 200 ng of wild-type U1A protein; lanes 6-8 contain 20,60, and $200 \mathrm{ng}$ of a mutant lacking residues 103-119; lanes 9-11 contain 20,60, and 200 ng of a mutant with residues 103-119 substituted by unrelated sequence. (D) A peptide containing U1A protein residues 103-115 inhibits PAP efficiently when conjugated to BSA. The peptide CGGGERDRKREKRKPKS, containing U1A residues 103-115 (in bold), was chemically synthesized. The ${ }^{32} \mathrm{P}$-labeled RNA substrate and polyadenylation conditions are as in C. (Lane 1) Input RNA; (lane 2) control polyadenylation; (lanes 3-5) as lane 2 with the addition of the U1A peptide conjugated to BSA. Lanes 6-11 are with the addition of BSA conjugated with control peptides: NLS CGGGPKKKRKVED (lanes 6-8) and NLSRev CGGGDEVKRKKKP (lanes 9-11). Lanes 12-14 contain the free monomeric U1A peptide with the amounts indicated in micrograms. 
these residues were also critical for PAP inhibition, recombinant U1A proteins with residues 103-119 either mutated or deleted were expressed in $E$. coli and purified. Whereas the wild-type UlA protein was able to inhibit PAP activity efficiently (Fig. 6C, lanes 1-5), the two mutant proteins had no effect on polyadenylation (lanes 6-11). Thus, amino acids 103-119 of U1A protein are required for both interaction with and inhibition of bovine PAP.

A peptide containing U1A protein residues $103-115$ is sufficient to inhibit PAP when conjugated to a carrier protein

Having demonstrated that residues 103-119 are critical for U1A protein to inhibit PAP we wished to determine whether they could be sufficient. To do this, it was necessary to overcome the requirement for RNA binding. Because only amino acids 103-115 of this region are conserved between human, mouse, and Xenopus UlA proteins, a peptide containing these residues was synthesized chemically and used in polyadenylation assays. The free monomeric peptide was unable to inhibit PAP activity even when used at 25000 -fold molar excess over PAP (Fig. 6D, lanes 12-14). Structural modeling of the $(\mathrm{U} 1 \mathrm{~A})_{2}$-PIE RNA complex predicts that amino acids $97-$ 115 of the two bound molecules of U1A would be in close proximity (see Discussion). In an attempt to simulate this proximity, the U1A peptide was conjugated to BSA to an average of 10-15 peptides per BSA molecule. In contrast to the free peptide, the peptide-BSA conjugate inhibited PAP activity efficiently; a five-fold molar excess of conjugate to PAP resulted in complete inhibition of polyadenylation (Fig. 6D, lanes 2-5). As a control of the specificity of inhibition we used two BSA-peptide conjugates containing either the SV40 T antigen NLS or a peptide containing the reverse amino acid sequence to the NLS (NLSRev). These peptides have very similar amino acid composition to, but different sequence than, the U1A peptide (see Fig. 6D legend). BSA conjugated to either NLS peptide or NLSREV peptide had little effect on PAP activity (Fig. 6D, lanes 6-11). The same efficiency of inhibition was observed when polyadenylation of several RNAs containing sequences unrelated to PIE RNA was assayed, demonstrating that the U1A peptide conjugate is not acting through a particular RNA sequence (data not shown). Further, the polyadenylation activity of a PAP mutant lacking the carboxyl terminus (PAP 1-586) was not affected by the conjugate (data not shown). These results confirm that PIE RNA is not essential for PAP inhibition and suggest a requirement for a high local concentration of the inhibitory U1A peptide for interaction with and inhibition of PAP.

\section{The U1A peptide conjugate uncouples splicing from cleavage and polyadenylation}

The interaction of U1A protein with PAP involves both the splicing and cleavage/polyadenylation machineries. As discussed in the Introduction, cases have been re- ported in which splicing and cleavage and polyadenylation on the same template are mutually stimulatory. However, the mechanism by which these two processing reactions are coupled remains unknown. The effect of the U1A peptide conjugate on a coupled splicing/polyadenylation reaction was therefore tested. Previous in vitro studies of coupling have used a substrate derived from SV40 that contains multiple binding sites for factors that influence the efficiency of $3^{\prime}$-end formation (see, e.g., Niwa et al. 1990; Niwa and Berget 1991; Wassarmann and Steitz 1993). We chose to construct a simpler pre-mRNA substrate in which the adenovirus I major late intron was fused upstream to the cleavage/polyadenylation signal from adenovirus L3 (Fig. 7A). A control substrate contained a single point mutation in the 3 '-end formation signal hexanucleotide (AAUAAA to AAGAAA). When these substrates were tested under conditions reported to allow coupling, there was a clear difference in splicing efficiencies between the two substrates (Fig. 7B, lanes 3,4; see Fig. 7C-E for a more detailed examination of the products. When the added $\mathrm{Mg}^{2+}$ levels were increased to uncouple cleavage and polyadenylation and splicing (Niwa et al. 1990; Niwa and Berget 1991) the stimulation of splicing by the wildtype cleavage and polyadenylation signal was lost (Fig. $7 \mathrm{~B}$, lanes 5,6). This higher level of $\mathrm{Mg}^{2+}$ did not affect the splicing efficiency of the mutant substrate (Fig. 7B, cf. lanes 4 and 6). Thus, the cleavage/polyadenylationsplicing coupling of this adenovirus-derived precursor exhibits similar properties to those reported previously.

Next, the effect of addition of the U1A peptide-BSA conjugate on the coupled reaction was determined. Addition of the UlA peptide conjugate abolished coupling of splicing and polyadenylation by reducing splicing efficiency of the wild-type substrate to that of the mutant substrate (Fig. 7C, cf. lanes 3-5 and lane 8). Figure 7 D and $\mathrm{E}$ show, respectively, a shorter exposure of the region of the gel where the spliced only or $3^{\prime}$ cleaved only products migrate and a lower section of the gel where the spliced and 3' cleaved product migrates. The control NLS-peptide conjugate (lane 6) had no effect on coupling. The U1A peptide conjugate did not have a general inhibitory effect on splicing because it affected neither the splicing efficiency of the wild-type substrate under high $\mathrm{Mg}^{2+}$ conditions where there is no coupling (Fig. 7C, lanes 14-16) nor splicing of the mutant substrate under the coupled reaction conditions (Fig. 7C, lanes 9-11). These reactions are carried out in the presence of $3^{\prime}$ $\mathrm{dATP}$ to prevent polyadenylation from obscuring the products of splicing. When no 3' dATP is included in the reaction, a perfect correlation was seen between the degree of inhibition of both polyadenylation and of the coupling reaction by the UlA peptide conjugate (data not shown), indicating that the U1A peptide conjugate-PAP interaction is occurring when coupling is lost. As a further demonstration of the specificity of the effect of the peptide on coupling as opposed to either splicing or the 3 ' cleavage reaction per se, the effect on the cleavage of a substrate containing only the AdL3 cleavage/polyadenylation signal, but no splice sites, was tested. Addition 

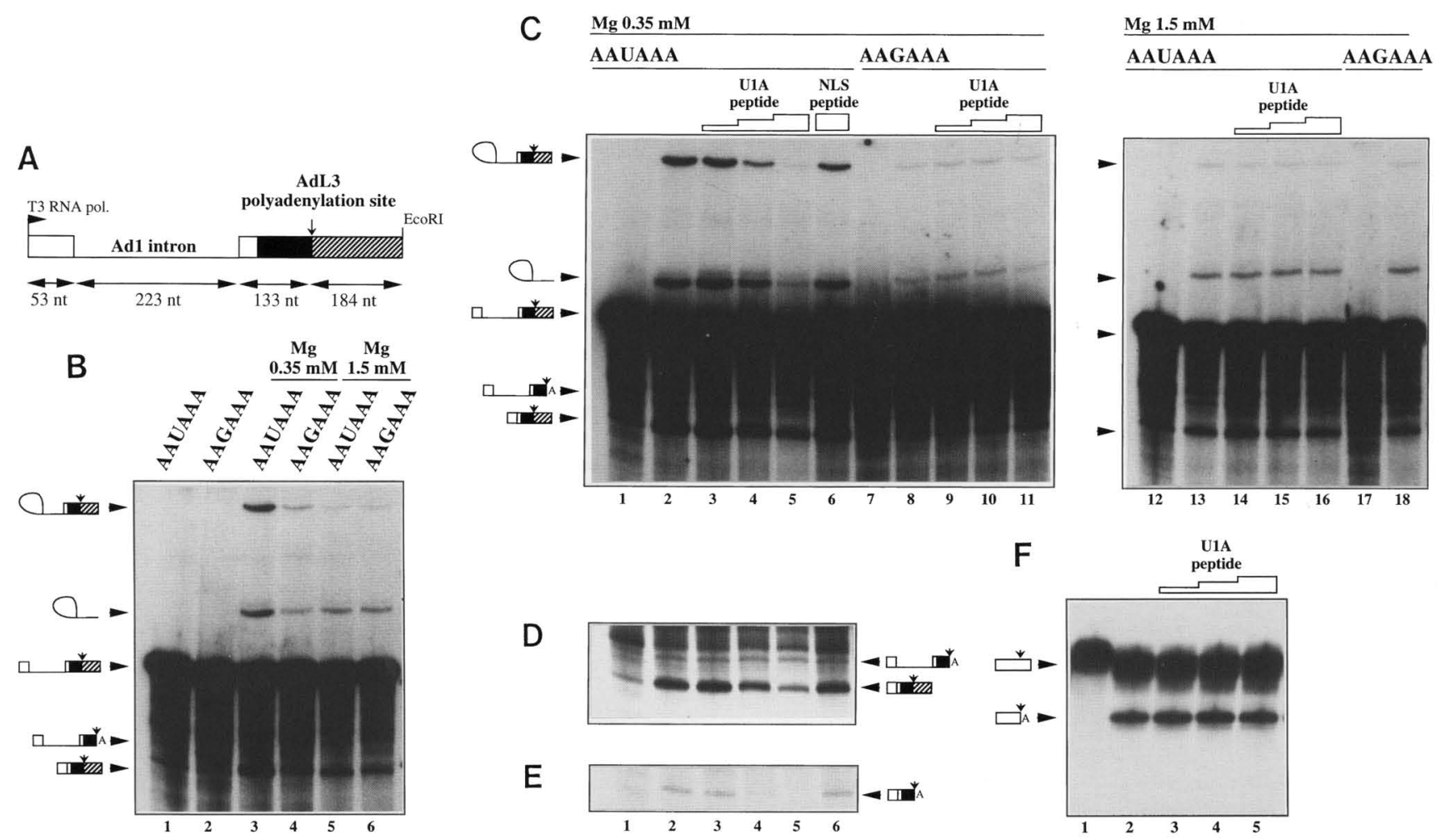

Figure 7. The U1A peptide specifically uncouples splicing from polyadenylation in vitro. $(A)$ A schematic of the substrates used. The adenovirus 1 major late intron splicing substrate was modified such that most of the $3^{\prime}$ exonic sequences were replaced by the adenovirus L3 polyadenylation region. As a control the identical substrate was constructed except for a point mutation in the cleavage and polyadenylation signal changing AAUAAA to AAGAAA, which inactivates the signal. $(B)$ Establishment of the conditions for coupling of splicing and polyadenylation in HeLa nuclear extracts. Lanes 1,3,5 contain ${ }^{32}$ P-labeled wild-type substrate; lanes 2,4,6 contain labeled mutant substrate. (Lanes 1,2) Nuclear extract is absent. (Lanes 3,4) Spliced products under low $\mathrm{Mg}^{2+}$ conditions where coupling is observed (Niwa and Berget 1991). (Lanes 5,6) Spliced products under high $\mathrm{Mg}^{2+}$ conditions where coupling between splicing and polyadenylation is not observed. The positions of the precursor RNA and products of the reaction are indicated on the left. $|C-E|$ Effect of various peptide-BSA conjugates on the coupled splicing and polyadenylation reaction. As in $B$ splicing reactions were performed in either low $\mathrm{Mg}^{2+}$ coupling conditions (lanes 2-11) or in high $\mathrm{Mg}^{2+}$ uncoupled conditions (lanes 13-18). (Lanes 1,7,12,17) Nuclear extract is absent. Lanes 1-6 and 12-16 contain labeled wild-type substrate, lanes 7-11, 17 and 18) contain labeled mutant substrate. In addition increasing amounts of U1A peptide conjugate were added: (lanes 3,9,14) $500 \mathrm{ng}$; $(1 \mathrm{anes} 4,10,15)$ 1000 ng, (lanes $5,11,16) 2000 \mathrm{ng}$. Lane 6 contains $2000 \mathrm{ng}$ of NLS peptide conjugate. The positions of the precursor RNA and products of the reaction are indicated, $D$ and $E$ are a shorter exposure of part of $C$ and a lower segment of the gel, respectively. $(D, E)$ The spliced or cleaved products. $(F)$ Cleavage of an AdL3 substrate in the presence of the U1A peptide conjugate. (Lane 1) Input RNA; (lane 2) in vitro cleavage of the L3-derived RNA; (lanes 3-5) in vitro cleavage in the presence of 500, 1000, and $2000 \mathrm{ng}$ of peptide conjugate, respectively.

of the peptide conjugate had no effect on $3^{\prime}$-end cleavage efficiency of this substrate (Fig. 7F, lanes 2-5). Note also that the peptide had no effect on the production of the cleavage-only product (Fig. 7D). We conclude that the U1A peptide conjugate, most probably via interaction with the carboxy-terminal end of PAP, causes uncoupling of cleavage and polyadenylation from intron splicing.

\section{Discussion}

To map precisely the interacting and inhibitory domains of each of the three components involved in UlA protein autoregulation a systematic mutational and biochemical analysis was performed. For bovine PAP a 20-amino-acid region was shown to be necessary and sufficient for inhibition of and interaction with RNA-bound U1A protein. These 20 amino acids are located at the extreme carboxy-terminal end of the protein, and are highly conserved among the known vertebrate PAPs (Fig. 4C), but not in the yeast PAPs. This region of the vertebrate enzyme is not required for basal PAP function (Raabe et al. 1994; Thuresson et al. 1994; Martin and Keller 1996), suggesting that the complex of the 20-amino-acid region with RNA-bound U1A protein must in some way influence the catalytic domain of the enzyme, located in the amino-terminal 520 amino acids. Transfer of this inhibitory 20-amino-acid fragment to Saccharomyces cerevisiae PAP rendered the fusion enzyme sensitive to inhibition by U1A protein. This suggests that, even if the inhibitory domain in PAP is not conserved, the region in 
the conserved catalytic domain responsible for inhibition must be present in yeast as well as bovine PAP.

The sequence of the U1A protein required for interaction with and inhibition of PAP consists of 13 amino acids conserved in vertebrate U1A proteins. When conjugated to a carrier protein, this peptide inhibits PAP enzyme activity, although the same monomeric peptide does not affect PAP, suggesting that a high local concentration of the peptide is required for inhibition. This provides an explanation for the requirement for two U1A binding sites on PIE RNA (van Gelder et al. 1993) or the artificial inhibitory RNA used here. The function of PIE RNA seems to be limited to bringing two molecules of U1A protein into a location near the $3^{\prime}$ end of the substrate RNA where contact with PAP is possible. Although the inhibitory amino acids of U1A lie just outside of the region of UlA whose structure in complex with RNA has been solved by NMR and X-ray crystallography (Oubridge et al. 1994; Allain et al. 1996), both models of the U1A protein-PIE RNA interaction place the amino-terminal ends of the two inhibitory peptides in very close proximity (Allain et al. 1996; Avis et al. 1996; Jovine et al. 1996). Thus, either the short carboxyterminal region of PAP required for its inhibition might interact with two separate copies of the UlA inhibitory sequence or the two UlA peptides might themselves interact to provide a single surface of interaction with PAP. Either explanation would be consistent with the observations that the peptide must be conjugated to a carrier protein to observe inhibition and that the 20-amino-acid domain of PAP is, as a GST fusion protein, capable of interacting only with two RNA-bound U1A molecules but not with a singly-bound U1A. The possibility that the UlA peptide might dimerize and present a single surface for interaction with PAP would provide an explanation for the lack of any apparent sequence duplication within the 20-amino-acid segment of PAP. Structural study is required to resolve the remaining questions about U1A protein-PAP interaction.

The U1A protein is found in splicing complexes, and PAP is required for 3 '-end processing. Interactions between components of these two pre-mRNA processing machineries are of interest because of the reported coupling between cleavage/polyadenylation and splicing of the 3'-most intron of some pre-mRNAs (Niwa et al. 1990; Niwa and Berget 1991; Nesic et al. 1993; Wassarmann and Steitz 1993; Nesic and Maquat 1994). This coupling has been proposed to reflect exon definition (Robberson et al. 1990; Niwa and Berget 1991; Berget 19951, a model for pre-mRNA processing in which interactions across exons, between the upstream 3 ' splice site and the downstream $5^{\prime}$ splice site, help to define and increase the excision rate of introns. For internal exons it has been shown that interactions between U1 snRNP bound to the downstream 5' splice site help to stabilize, albeit indirectly, binding of U2AF to the polypyrimidine tract of the upstream 3' splice site (Robberson et al. 1990; Hoffman and Grabowski 1992). Two natural exceptions to the exon definition model are represented by the first and last exons that lack either an upstream $3^{\prime}$ splice site or a downstream $5^{\prime}$ splice site, respectively. For recognition of the first exon, it has been shown recently that interactions between cap-binding proteins and the cap proximal 5' splice site are important (Izaurralde et al. 1994; Colot et al. 1996; Lewis et al. 1996a,b), and for the last exon evidence exists that the cleavage and polyadenylation machinery is required for efficient recognition (Niwa et al. 1990; Niwa and Berget 1991; Nesic et al. 1993; Wassarmann and Steitz 1993; Nesic and Maquat 1994). Although the molecular nature of the mediators of these different interactions is almost certainly diverse (see the cited references), it is of interest that evidence for a role of the U1 snRNP in coupling between splicing and 3 '-end formation has been presented (Wassarman and Steitz 1993).

The molecular nature of the interactions responsible for coupling of splicing of the last intron with the cleavage and polyadenylation reaction is not known. Previous work has revealed an interaction between U1A protein and CPSF that increases the AAUAAA-binding and polyadenylation-stimulating activity of CPSF (Gunderson et al. 1994; Lutz et al. 1996), but it is unclear whether this plays any role in the coupling phenomenon. In contrast, the data presented here show that the inhibitory U1A peptide conjugate that interacts with PAP specifically reverses coupling of splicing and polyadenylation, without having any effect on the splicing efficiency of a noncoupled intron substrate or on cleavage of a non-coupled 3 ' end formation substrate. Although we cannot absolutely rule out the possibility that the peptide conjugate might interact not only with PAP, but also with some other unidentified factor required for coupling, the simplest interpretation of this experiment is that coupling between splicing and polyadenylation is inhibited by blocking interaction with the carboxy-terminal domain of PAP, that is, the region of PAP required for U1A autoregulation. We cannot say whether U1A is the partner of PAP in coupling, but given that two copies of U1A are essential for PAP interaction and that U1 snRNP contains a single UlA molecule, we think this is unlikely.

Our data therefore suggest that the carboxyl terminus of PAP is required for the coupling of splicing and polyadenylation, and that the same region of the polymerase seems to be capable of mediating both positive and negative regulatory effects on pre-mRNA processing. Although this may seem contradictory there are examples of regulatory proteins having both positive and negative effects on gene expression. For example, the transcription factor Kruppel can either stimulate or repress transcription depending on whether it is in a monomeric or dimeric form (Sauer et al. 1995). Interestingly, Krüppel does this by interacting with different components of the basal transcription machinery depending on which oligomeric state it is in. Taking this as an example, it is not unreasonable to propose that interaction between U1A and PAP, both members of the basal RNA processing machinery, or between PAP and other splicing factors, could also have stimulatory as well as inhibitory activities. We have now characterized in detail how U1A protein represses the polyadenylation reaction. However, 
much work remains in order to understand the proposed involvement of PAP in the coupling of splicing and cleavage and polyadenylation.

\section{Materials and methods}

Recombinant U1A proteins, PAPS, and GST-His fusions

The yeast, bovine and yeast-bovine hybrid PAPs were histidinetagged at the carboxyl terminus and purified by $\mathrm{Ni}^{2+}$-NTA chromatography as described (Martin and Keller 1996). Other mutant histidine-tagged U1A proteins $(\Delta 103-119$ and replacement of 103-119 with the sequence LLALGLPLLPLAVPLQA) were purified from E. coli using $\mathrm{Ni}^{2+}$-NTA and MonoS chromatography. The carboxy-terminal histidine tag not only facilitated purification of PAP, but had the additional advantage of ensuring that all of the carboxy-terminal residues were present after purification. This procedure was found to be essential to obtain nondegraded preparations of some of the hybrid and mutant polymerases used in Figure 4. Independent of the presence and location of the tag the mutant bovine PAPs had approximately the same specific polyadenylation activity as the wild-type protein. The bovine PAP where residues $732-739$ were mutated replaced the naturally occuring residues with PIQSQFYL. The various recombinant PAPs were $20 \%-90 \%$ pure as judged by Coomassie staining of SDS gels and their integrity verified by Western blotting using antibodies raised against either yeast or bovine PAP (from W. Keller, Biocentrum, Basel, Switzerland). The various GST-His proteins fused to PAP sequences were expressed in E. coli and purified to homogeneity by consecutive glutathione-agarose, $\mathrm{Ni}^{2+}$-NTA and MonoS chromatography.

\section{Plasmids}

AgWTPre, used to make PIE RNA, was described elsewhere (Gunderson et al.,1994). $T_{7}$ transcripts contain 110 nucleotides of U1A pre-mRNA and ten $5^{\prime}$ and five $3^{\prime}$ nucleotides of vector RNA. Loop mutants ( $\Delta$ loop1, $\Delta$ loop2, and the double mutant $\Delta$ loop1/2) were described previously (van Gelder et al. 1993). The SL2/SL2 RNA replaces the 5 '-most 45 nucleotides of PIE RNA (see Fig. 1) with the sequence given in Figure 2A. Singleloop mutants ( $\Delta$ SL2/SL2 and SL2/ SSL2) and the double mutant $(\Delta S L 2 / \Delta S L 2)$ of the SL2/SL2 RNA replace one or both of the seven-nucleotide loops, AUUGCAC, with AGGAUCC. The ${ }^{32}$ P-labeled RNAs were gel-purified prior to use. For E. coli expression of the PAP and U1A proteins and mutants thereof, the respective cDNAs were cloned into a derivative of the $\mathrm{pET} 3$ vector (Wahle 1991a). For GST-HIS proteins, the vector pGEX$2 \mathrm{~T}$ (Smith and Johnson 1988) was modified by attaching a 6-histidine tag at the carboxy-terminal EcoRI site to make a GSTHIS construct. GST-HIS fusions with PAP sequences were constructed by PCR amplification using BamHI linker oligonucleotides complementary to the appropriate PAP cDNA sequences. The fragments were then inserted into the $\mathrm{BamHI}$ site of the GST-HIS vector. The plasmid pBSAd211 contains 326 nucleotides of the adenovirus I major late intron fused upstream to a 267-nucleotides fragment containing the AdL3 cleavage and polyadenylation site (see Fig. 7A). The plasmid pBSAd212 is identical in sequence to pBSAd211 but contains a point mutation in the polyadenylation signal changing AAUAAA to AAGAAA. The AdL3 substrate is that described by Boelens et al. (1993) with the sequence CCTGCAGCAACTAA inserted at position 228 .

\section{$U 1 A$ protein and $P A P$ interaction assays}

The interaction assay using bovine PAP coupled to Affigel-15 was as described (Gunderson et al. 1994). For the gel mobility shift assay the U1A protein was first incubated with ${ }^{32} \mathrm{P}$-labeled PIE RNA. The 16- $\mu 1$ reaction contained the nonspecific polyadenylation assay buffer except that ATP was omitted. After incubation at $20^{\circ} \mathrm{C}$ for $5 \mathrm{~min}$ the various GST-HIS fusion proteins or their storage buffer was added and the reaction incubated $5 \mathrm{~min}$ at $20^{\circ} \mathrm{C}$ and then loaded onto a native $6 \%(60: 1)$ $1 \times$ TBE polyacrylamide gel that had been prerun $30 \mathrm{~min}$ at room temperature at $13 \mathrm{~V} / \mathrm{cm}$. After $2 \mathrm{hr}$ the gel was stopped, dried, and the labeled RNA visualized by autoradiography.

\section{Cleavage/polyadenylation assays}

Nuclear extracts were prepared from HeLa cells by the procedure of Dignam et al., (1983). Substrate RNAs were transcribed by T3 RNA Polymerase and $\mathrm{m} 7 \mathrm{GpppG}$ capped. Coupled reactions were as described by Edery and Sonenberg (1985) with the following modifications. The added $\mathrm{MgCl}_{2}$ concentration was varied from 0.35 to $1.5 \mathrm{~mm}$ and each reaction contained $3^{\prime} \mathrm{dATP}$ to visualize RNA products that had undergone $3^{\prime}$-end cleavage. Where indicated, the free U1A peptide or the various peptideBSA conjugates were added at the beginning of the reaction just prior to addition of the labeled RNA substrate. After $2 \mathrm{hr}$ at $30^{\circ} \mathrm{C}$ the reactions were extracted using proteinase $\mathrm{K}$ followed by phenol-chloroform extraction and ethanol precipitation and the spliced products separated on a denaturing $10 \%(60: 1)$ polyacrylamide gel. The cleavage assay was as described (Boelens et al. 1993).

Both specific (using HeLa nuclear extracts) and nonspecific (using only recombinant $\mathrm{PAP}$ ) polyadenylation assays were performed in $25 \mu \mathrm{l}$ reactions as described (Gunderson et al. 1994). The conditions of the nonspecific reaction were slightly modified to contain the following: $3 \mu \mathrm{g}$ of BSA, $1 \mu \mathrm{g}$ tRNA, $20 \mathrm{~mm}$ Tris at pH7, $60 \mathrm{~mm} \mathrm{KCl}, 0.1 \mathrm{~mm}$ EDTA, $5 \mathrm{~mm} \mathrm{DTT}, 5$ units of RNasin (Promega), $0.7 \mathrm{~mm} \mathrm{MnCl}_{2}, 0.5 \mathrm{~mm} \mathrm{ATP,} \mathrm{10 \%} \mathrm{glycerol,}$ and $0.05 \%$ Triton X-100.

\section{Peptides and BSA conjugates}

The U1A peptide consisted of the following sequence: CGGGERDRKREKRKPKS; the amino acids in bold are U1A residues $103-115$. The peptide was stored at $20 \mathrm{mg} / \mathrm{ml}$ in GHK100 buffer (10\% glycerol, $30 \mathrm{~mm}$ HEPES at $\mathrm{pH} 8.0,100 \mathrm{~mm} \mathrm{KCl}$ and $2 \mathrm{~mm}$ DTT). Conjugation to BSA of the peptides used $5 \mathrm{mg}$ of BSA dissolved in $1 \mathrm{ml} \mathrm{PBS} \mathrm{pH} \mathrm{7.4} \mathrm{and} \mathrm{incubated} \mathrm{for} 1 \mathrm{hr}$ at $20^{\circ} \mathrm{C}$ with $8 \mathrm{mg}$ sulfosuccinimidyl $4-(\mathrm{N}$-maleimidomethyl)cyclohexane-1carboxylate (sulfo-SMCC, Pierce). Unreacted sulfo-SMCC was removed on a Sephadex G-50 column. The purified BSA was gently mixed with $5 \mathrm{mg}$ of peptide dissolved in $1 \mathrm{ml}$ PBS at $\mathrm{pH}$ 6.5 and incubated overnight at $4^{\circ} \mathrm{C}$. Conjugation was assessed by SDS-PAGE. BSA-peptide conjugates were concentrated in a minicon 30 concentrator (Amicon) and stored in GHK100.

\section{Acknowledgments}

We thank Gert-Jan Arts, Puri Fortes, Chiara Gamberi, Fatima Gebauer, Matthias Hentze, Bertrand Seraphin, and Juan Valcárcel for critical reading of the manuscript, Joe Lewis for nuclear extracts and advice on chromatography, Michael Rosbash for suggesting the two hairpin experiment, and Walter Keller for antibodies to bovine and yeast PAPs. The work was supported by the Deutsche Forschungsgemeinschaft, European Molecular Biology Organization and European Molecular Biology Laboratory.

The publication costs of this article were defrayed in part by 
payment of page charges. This article must therefore be hereby marked "advertisement" in accordance with 18 USC section 1734 solely to indicate this fact.

\section{References}

Allain, F.H.-T., C.C. Gubser, P.W.A. Howe., K. Nagai, D. Neuhaus, and G. Varani. 1996. Specificity of ribonucleoprotein interaction determined by RNA folding during complex formation. Nature 380: 646-650.

Avis, J.M., F.H.-T. Allain, P. Howe, G. Varani, K. Nagai, and D. Neuhaus. 1996. Solution structure of the N-terminal RNP domain of UlA protein: The role of the C-terminal residues in structure stability and RNA binding. I. Mol. Biol. 257: 398-411.

Ballantyne, S., A. Bilger, J. Astrom, A. Virtanen., and M. Wickens. 1995. Poly(A) polymerase in the nucleus and cytoplasm of frog oocytes: Dynamic changes during oocyte maturation and early development. RNA 1: 64-78.

Berget, S.M. 1995. Exon recognition in vertebrate splicing. $J$. Biol. Chem. 270: 2411-2414.

Bienroth, S., E. Wahle, C. Suter-Crazzolara, and W. Keller. 1991. Purification of the cleavage and polyadenylation factor involved in 3 '-processing of messenger RNA precursors. I. Biol. Chem. 266: 19768-19776.

Boelens, W.C., E.J.R. Jansen, W.J. van Venrooij, R.Stripecke, I.W. Mattaj, and S.I. Gunderson. 1993. The human Ul snRNP-specific U1A protein inhibits polyadenylation of its own pre-mRNA. Cell 72: 881-892.

Burd, C.G. and G. Dreyfuss. 1994. Conserved structures and diversity of functions of RNA-binding proteins. Science 265: 615-621.

Christofori, G. and W. Keller. 1988. 3' cleavage and polyadenylation of mRNA precursors in vitro requires a poly(A) polymerase, a cleavage factor, and a snRNP. Cell 54: 875889.

Colot, H.V., F. Stutz, and M. Rosbash. 1996. The yeast splicing factor Mud13p is a commitment complex component and corresponds to CBP20, the small subunit of the nuclear capbinding complex. Genes \& Dev. 10: 1699-1708.

Dignam, J.D., R.M. Lebovitz, and R.R. Roeder. 1983. Accurate transcription initiation by RNA polymerase II in a soluble extract fom isolated mammalian nuclei. Nucleic Acids Res. 11: $1475-1489$.

Edery, I. and N. Sonenberg. 1985. Cap-dependent RNA splicing in a HeLa cell nuclear extract. Proc. Natl. Acad. Sci. 82: $7590-7594$.

Gilmartin, G.M. and J.R. Nevins. 1991. Molecular analyses of 2 poly(A) site-processing factors that determine the recognition and efficiency of cleavage of pre-mRNA. Mol. Cell. Biol. 11: $2432-2438$.

Gunderson, S.I., K. Beyer, G. Martin, W. Keller, W.C. Boelens, and I.W. Mattaj. 1994. The human U1A snRNP protein regulates polyadenylation via a direct interaction with poly(A) polymerase. Cell 76: 531-541.

Hamm, J., N.A. Dathan, D. Scherly, and I.W. Mattaj. 1990. Multiple domains of U1 snRNA, including U1 specific protein binding sites, are required for splicing. EMBO I. 9: 12371244.

Hashimoto, C. and J.A. Steitz. 1986. A small nuclear ribonucleoprotein associates with the AAUAAA polyadenylation signal in vitro. Cell 45: 581-591.

Hoffman, B.E. and P.J. Grabowski. 1992. U1 snRNP targets an essential splicing factor, U2AF65, to the $3^{\prime}$ splice site by a network of interactions spanning the exon. Genes \& Dev.
6: $2554-2568$

Hoffman, D.W., C.C. Query, B.L. Golden, S.W. White, and J.D. Keene. 1991. RNA-binding domain of the A protein component of the U1 small nuclear ribonucleoprotein analyzed by NMR spectroscopy is structurally similar to ribosomal proteins. Proc. Nat1. Acad. Sci. 88: 2495-2499.

Izaurralde, E., J. Lewis, C. McGuigan, M. Jankowska, E. Darzynkiewicz, and I.W. Mattaj. 1994. A nuclear cap binding protein complex involved in pre-mRNA splicing. Cell 78: 657-668.

Jovine, L., C. Oubridge, J.M. Avis, and K. Nagai. 1996. Two structurally different RNA molecules are bound by the spliceosomal protein UlA using the same recognition strategy. Structure 4: 621-631.

Keller, W. 1995. No end yet to messenger RNA 3' processing. Cell 81: 829-832.

Lewis, J.D., S.I. Gunderson, and I.W. Mattaj.1995. The influence of $5^{\prime}$ and $3^{\prime}$ end structures on pre-mRNA metabolism. J. Cell Sci. 19: 13-19.

Lewis, J.D., E. Izaurralde, A. Jarmolowski, C. McGuigan, and I.W. Mattaj. 1996a. A nuclear cap-binding complex facilitates association of U1 snRNP with the cap-proximal 5' splice site. Genes \& Dev. 10: 1683-1698.

Lewis, J.D., D. Görlich, and I.W. Mattaj. 1996b. A yeast cap binding protein complex (yCBC) acts at an early step in premRNA splicing. Nucleic Acids Res. 24: 3332-3336.

Liao, X.C., J. Tang, and M. Rosbash. 1993. An enhancer screen identifies a gene that encodes the yeast U1 snRNP A protein: Implications for snRNP protein function in pre-mRNA splicing. Genes \& Dev. 7: 419-428.

Lu, J. and K.B. Hall. 1995. An RBD that does not bind RNA: NMR secondary structure determination and biochemical properties of the C-terminal RNA binding domain from the human U1A protein. I. Mol. Biol. 247: 739-752.

Lutz, C.S., K.G. Murthy, N. Schek, J.P. O'Connor, J.L. Manley, and J.C. Alwine. 1996. Interaction between the U1 snRNP-A protein and the $160-\mathrm{kD}$ subunit of cleavage-polyadenylation specificity factor increases polyadenylation efficiency in vitro. Genes \& Dev. 10: 325-337.

Lutz-Freyermuth, C., C.C. Query, and J.D. Keene. 1990. Quantitative determination that one of two potential RNA-binding domains of the A protein component of the Ul small nuclear ribonucleoprotein complex binds with high affinity to stem-loop II of U1 RNA. Proc. Nat1. Acad. Sci. 87: 63936397.

MacDonald, C.C., J. Wilusz, and T. Shenk. 1994. The 64-kilodalton subunit of the CstF polyadenylation factor binds to pre-mRNAs downstream of the cleavage site and influences cleavage site location. Mol. Cell. Biol. 14: 6647-6654.

Manley, J.L. 1995. Messenger RNA polyadenylation: A universal modification. Proc. Natl. Acad. Sci. 14: 1807-1811.

Manley, J.L. and N.J. Proudfoot. 1994. RNA 3' ends: Formation and function. Genes \& Dev. 8: 259-264.

Martin, G. and W. Keller. 1996. Mutational analysis of mammalian poly(A) polymerase identifies a region for primer binding and a catalytic domain, homologous to the family $\mathrm{X}$ polymerases, and to other nucleotidyltransferases. EMBO $J$. 15: 2593-2603.

Mattai, I.W. 1993. RNA recognition: A family matter? Cell 73: $837-840$.

Moore, C.L. and P.A. Sharp. 1985. Accurate cleavage and polyadenylation of exogenous RNA substrate. Cell 41: 845-855.

Murthy, K.G.K. and J.L. Manley. 1992. Characterization of the multisubunit cleavage-polyadenylation specificity factor from calf thymus. J. Biol. Chem. 267: 14804-14811.

Nagai, K., C. Oubridge, T.H. Jessen, J. Li, and P.R. Evans. 1990. 
Crystal structure of the RNA-binding domain of the U1 small nuclear ribonucleoprotein A. Nature 348: 515-520.

Nesic, D. and L.E. Maquat. 1994. Upstream introns influence the efficiency of final intron removal and RNA 3 '-end formation. Genes \& Dev 8: 363-375.

Nesic, D., J. Cheng, and L.E. Maquat. 1993. Sequences within the last intron function in RNA 3 '-end formation in cultured cells. Mol. Cell. Biol. 13: 3359-3369.

Niwa, M. and S.M. Berget. 1991. Mutation of the AAUAAA polyadenylation signal depresses in vitro splicing of proximal but not distal introns. Genes \& Dev. 5: 2086-2095.

Niwa, M., S.D. Rose and S.M. Berget. 1990. In vitro polyadenylation is stimulated by the presence of an upstream intron. Genes \& Dev. 4: 1552-1559.

Oubridge, C., N. Ito, P.R. Evans, C.H. Teo, and K. Nagai. 1994. Crystal structure at $1.92 \AA$ resolution of the RNA-binding domain of the U1A spliceosomal protein complexed with an RNA hairpin. Nature 372: 432-438.

Proudfoot, N. 1994. Post-transcriptional regulation. Chasing your own poly(A) tail. Curr. Biol, 4: 359-361.

Proudfoot, N.J. and G.G. Brownlee. 1976. 3' Non-coding region sequences in eukaryotic messenger RNA. Nature 263: 211214

Raabe, T., F.J. Bollum, and J.L. Manley. 1991. Primary structure and expression of bovine poly (A) polymerase. Nature 353: 229-234.

Raabe, T., K.G.K. Murthy, J.L. Manley. 1994. Poly(A) polymerase contains multiple functional domains. Mol. Cell. Biol. 14: 2946-2957.

Raju, V.S. and S.T. Jacob. 1988. Association of poly|A) polymerase with U1 RNA. I. Biol. Chem. 263: 11067-11070.

Robberson, B.L., G. Cote, and S.M. Berget. 1990. Exon definition may facilitate splice site selection in RNAs with multiple exons. Mol. Cell. Biol. 10: 84-94.

Rüegsegger, U., K. Beyer, and W. Keller. 1996. Purification and characterization of human cleavage factor involved in the $3^{\prime}$ end processing of messenger RNA precursors. J. Biol. Chem. 271: 6107-6113.

Sauer, F., J.D. Fondell, Y. Ohkuma, R.G. Roeder, and H. Jackle. 1995. Control of transcription by Kruppel through interactions with TFIIB and TFIIE beta. Nature 375: 162-164.

Scherly, D., W. Boelens, W.J. van Venrooij, N.A. Dathan, J. Hamm, and I.W. Mattaj. 1989. Identification of the RNA binding segment of human U1A protein and definition of its binding site on U1 snRNA. EMBO T. 8: 4163-4170.

Scherly, D., W. Boelens, N.A. Dathan, W.J. van Venrooij, and I.W. Mattaj. 1990. Major determinants of the specificity of interaction between small nuclear ribonucleoproteins U1A and U2B" and their cognate RNAs. Nature 345: 502-506.

Sillekens, P.T.G., W.J. Habets, R.P. Beijer, and W.J. van Venrooij. 1987. cDNA cloning of the human U1 snRNA-associated A protein: Extensive homology between U1 and U2 snRNP-specific proteins. EMBO J. 6: 3841-3848.

Smith, D.B. and Johnson, K.S. 1988. Single step purification of polypeptides expressed in Escherichia coli as fusions with glutathione S-transferase. Gene 67: 31-40.

Stump, W.T. and K.B. Hall. 1995. Crosslinking of an iodo-uridine-RNA hairpin to a single site on the human U1A Nterminal RNA binding domain. RNA 1: 55-63.

Takagaki, Y., L.C. Ryner, and J.L. Manley. 1989. Four factors are required for $3^{\prime}$-end cleavage of pre-mRNAs. Genes \& Dev. 3: $1711-1724$.

Takagaki, Y., J.L. Manley, C.C. MacDonald, J. Wilusz, T. Shenk. 1990. A multisubunit factor, CstF, is required for polyadenylation of mammalian pre-mRNAs. Genes \& Dev. 4: 21122120 .
Tang, J. and M. Rosbash. 1996. Characterization of yeast U1 snRNP A protein: Its binding site and function in splicing. RNA 2: $1058-1070$.

Thuresson, A-C., J. Åstrom, A. Åstrom, K.O. Grovnik, and A. Virtanen. 1994. Multiple forms of poly(A) polymerase in human cells. Proc. Nat1. Acad. Sci. 91: 979-983.

van Gelder, C.W.G., S.I. Gunderson, E.J.R. Jansen, W.C. Boelens, M. Polycarpou-Schwarz, I.W. Mattaj, and W.J. van Venrooij. 1993. A complex secondary structure in U1A premRNA that binds two molecules of U1A protein is required for regulation of polyadenylation. EMBO J. 12: 5191-5200.

Wahle, E. 1995. 3'-end cleavage and polyadenylation of mRNA precursors. Biochim. Biophys. Acta. 1261: 183-194.

Wahle, E. 1991a. Purification and characterization of a mammalian polyadenylate polymerase involved in the $3^{\prime}$ end processing of messenger RNA precursors. I. Biol. Chem. 266: 3131-3139.

Wahle, E. 1991b. A novel poly(A)-binding protein acts as a specificity factor in the second phase of messenger RNA polyadenylation. Cell 66: 759-768.

Wahle, E., G. Martin., E. Schiltz, and W. Keller. 1991. Isolation and expression of cDNA clones encoding mammalian poly(A) polymerase. EMBO T. 10: 4251-4257.

Wassarman, K.M. and J.A. Steitz. 1993. Association with terminal exons in pre-mRNAs: A new role for the U1 snRNP? Genes \& Dev. 7: 647-59. 


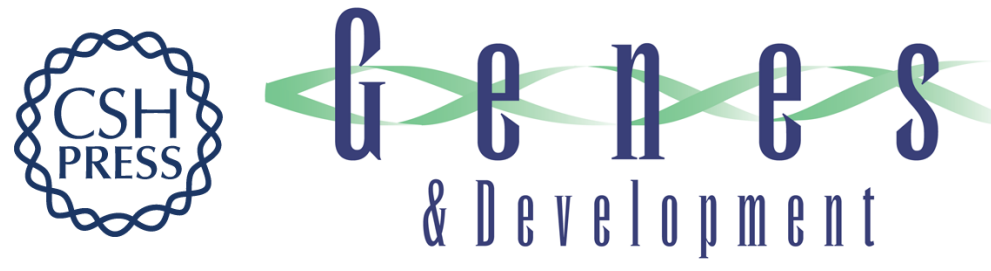

\section{Involvement of the carboxyl terminus of vertebrate poly(A) polymerase in U1A autoregulation and in the coupling of splicing and polyadenylation.}

S I Gunderson, S Vagner, M Polycarpou-Schwarz, et al.

Genes Dev. 1997, 11:

Access the most recent version at doi:10.1101/gad.11.6.761

\section{License}

Email Alerting Receive free email alerts when new articles cite this article - sign up in the box at the top Service right corner of the article or click here.

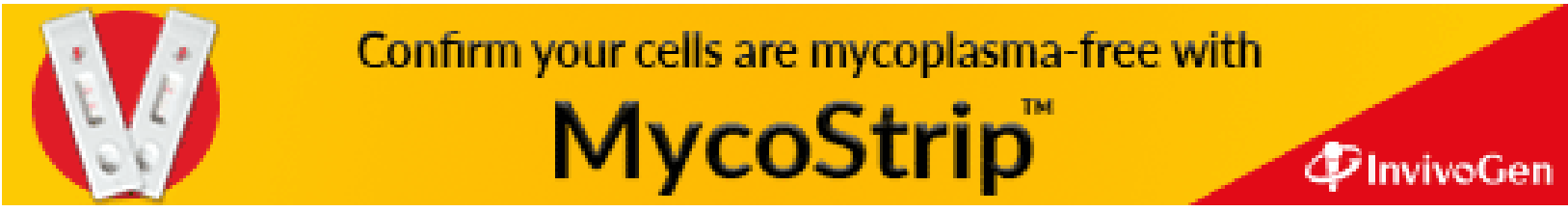

